SECTION 7. Mechanics and machine construction.

Kestelman Vladimir Nikolayevich Doctor of technical Sciences, Professor, Specialty Scientific Consultant, Russian Technology Initiative, LTD, President of KVN International, Inc., Philadelphia, Member of Mid-Atlantic-Russia Business Council and of International Visitors Council of Philadelphia, King of Prussia, Pennsylvania, USA

\begin{abstract}
Arne Jönsson deputy CEO and manages the language technology research activities at Sics East Swedish ICT, Professor of Computer Science, Linköping University, Director of undergraduate studies for the Cognitive Science program, Deputy CEO at Santa Anna, Sweden

Shevtsov Alexandr Nikolayevich candidate of technical Sciences, President, Theoretical \& Applied Science, LLP, associate Professor of the Department «Applied mathematics» Taraz State University named after M.Kh. Dulati, Kazakhstan
\end{abstract}

\title{
ON SOME DEPENDENCIES STATISTICAL METHODS FOR MODELING OF LONG-TERM STRENGTH OF POLYMERS.
}

Purpose of the article is to study the processes of thermo-fluctuation degradation of polymer chains without loading.

Key words: polymer, fluctuation, destruction.

\section{О НЕКОТОРЫХ ЗАВИСИМОСТЯХ СТАТИСТИЧЕСКИХ МЕТОДОВ МОДЕЛИРОВАНИЯ ДЛИТЕЛЬНОЙ ПРОЧНОСТИ ПОЛИМЕРОВ.}

Цель статьи изучение прочессов термофлуктуащионной деструкции полимерных цепочек без нагружения.

Ключевые слова: полимер, флуктуачия, деструкиия. 
При изучении динамических аспектов прочности и долговечности стеклопластиковых трубопроводов с полимерным связующим, на первый план выходят адгезионные характеристики роувинга и долговечность полимера, по результатам статических испытаний, а также экспериментальные физические параметры температурно-временной зависимости прочности (ТВЗП). Для корректной обработки экспериментальных результатов применяют современные методы математической статистики. Хотя многие ученые (экспериментаторы) не применяя их, сталкиваются с проблемами и разрабатывают надуманные теории и методы, не углубляясь в математическую природу явлений ТВЗП и проявлений моделей хрупкого и квазихрупкого разрушения [1]. Рассмотрим некоторые вопросы построения и статистического анализа различных моделей ТВЗП полимеров на основе современных методов многомерной математической статистики.

Существующие модели ТВЗП полимеров:

- Регрессионная модель Журкова,

- Регрессионная модель Регеля-Ратнера,

- Регрессионная модель Бартенева,

- Регрессионная модель Ратнера.

Для каждой из них получены, соответственно, формулы нахождения долговечности в условиях положительных и отрицательных дилатаций.

$$
\begin{gathered}
\tau=\tau_{0} \exp \left(\frac{U_{0}-\gamma \sigma}{k T}\right), \\
\tau=\tau_{0} \exp \left(\left(U_{0}-\gamma \sigma\right)\left(\frac{1}{k T}-\frac{1}{k T_{n}}\right)\right), \\
\tau=A \sigma^{-m} \exp \left(\frac{U_{0}}{k T}\right), \\
\tau=A \exp \left(\frac{U_{0}}{k T}-\alpha \sigma\right) .
\end{gathered}
$$

Валишиным А.А. предлагается единая обобщенная регрессионная модель, содержащая в себе все 4 приведенные частные модели [1, С.373]:

$$
\overline{w_{j}}=\beta_{0}+\beta_{1} x_{j}+\beta_{2} y_{j}+\beta_{12} x_{j} y_{j}+\overline{\varepsilon_{j}}, \quad j=\overline{1, N} .
$$

Рассмотрим эти модели по по очереди.

1) Преобразуем выражение (1): 


$$
\begin{aligned}
& \tau=\tau_{0} \exp \left(\frac{U_{0}-\gamma \sigma}{k T}\right)=\tau_{0} \exp \left(\frac{U_{0}}{k T}-\frac{\gamma \sigma}{k T}\right)= \\
& =\tau_{0} \frac{\exp \left(\frac{U_{0}}{k T}\right)}{\exp \left(\frac{\gamma \sigma}{k T}\right)}=\tau_{0} \exp \left(\frac{U_{0}}{k T}\right) \cdot\left(\frac{1}{\exp \left(\frac{\gamma \sigma}{k T}\right)}\right)=\exp \left(\frac{U_{0}}{k T}\right) \cdot\left(\frac{\tau_{0}}{\exp \left(\frac{\gamma \sigma}{k T}\right)}\right)
\end{aligned}
$$

В результате получим

$$
\tau=S_{1} \exp \left(\frac{U_{0}}{k T}\right), \text { где } S_{1}=\left(\frac{\tau_{0}}{\exp \left(\frac{\gamma \sigma}{k T}\right)}\right) .
$$

2) Преобразуем выражение (2):

$$
\begin{aligned}
& \tau=\tau_{0} \exp \left(\left(U_{0}-\gamma \sigma\right)\left(\frac{1}{k T}-\frac{1}{k T_{n}}\right)\right)=\tau_{0} \exp \left(\frac{U_{0}}{k T}-\frac{U_{0}}{k T_{n}}-\gamma \sigma\left(\frac{1}{k T}-\frac{1}{k T_{n}}\right)\right)= \\
& =\tau_{0} \exp \left(\frac{U_{0}}{k T}\right) \exp \left(\frac{\gamma \sigma}{k T_{n}}-\frac{U_{0}}{k T_{n}}-\frac{\gamma \sigma}{k T}\right)=\exp \left(\frac{U_{0}}{k T}\right) \cdot\left(\frac{\tau_{0} \exp \left(\frac{\gamma \sigma}{k T_{n}}\right)}{\left.\exp \left(\frac{U_{0}}{k T_{n}}\right) \exp \left(\frac{\gamma \sigma}{k T}\right)\right)}\right.
\end{aligned}
$$

В результате получим

$$
\tau=S_{2} \exp \left(\frac{U_{0}}{k T}\right), \text { где } S_{2}=\left(\frac{\tau_{0} \exp \left(\frac{\gamma \sigma}{k T_{n}}\right)}{\exp \left(\frac{U_{0}}{k T_{n}}\right) \exp \left(\frac{\gamma \sigma}{k T}\right)}\right)
$$

3) Преобразуя выражение (3), получим:

$$
\tau=S_{3} \exp \left(\frac{U_{0}}{k T}\right), \text { где } S_{3}=A \sigma^{-m} \text {. }
$$

4) Преобразуя выражение (4), получим:

$$
\tau=A \exp \left(\frac{U_{0}}{k T}-\alpha \sigma\right)=A \frac{\exp \left(\frac{U_{0}}{k T}\right)}{\exp (\alpha \sigma)}=\exp \left(\frac{U_{0}}{k T}\right) \cdot\left(\frac{A}{\exp (\alpha \sigma)}\right),
$$

и окончательно: 


$$
\tau=S_{4} \exp \left(\frac{U_{0}}{k T}\right), \text { где } S_{4}=\left(\frac{A}{\exp (\alpha \sigma)}\right) .
$$

Получаем обобщенную формулу с помощью которой можно описать все 4 модели:

$$
\tau=S_{i} \exp \left(\frac{U_{0}}{k T}\right), \text { где } i=\overline{1,4}
$$

Рассмотрим (5) более подробно, здесь введены следующие постоянные:

$k$ - постоянная Больцмана $\left(k=1,3806488(13) \times 10^{-23}\right.$ Дж $\left./ K\right)$,

$T$ - температура (в Кельвинах),

$U_{0}$ - энергия активации разрушения связей полимерных молекул ( энергетический барьер процесса флуктуационного перехода),

$A$ - предэкспонециальный член, включающий в скрытом виде зависимость вязкости от других параметров структуры, в частности молекулярной массы [2].

В полимере имеется широкий набор межатомных связей [3]. Вдоль молекулярной цепи полимеров атомы соединены ковалентными связями; так же связаны боковые атомы водорода и их заместители с атомами основной полимерной цепи.

\section{Энергия этих связей - около 330 кДж/моль.}

Между макромолекулами в термопластичных полимерах образуются либо водородные связи (10...40 кДж/моль), либо еще более слабые межмолекулярные ван-дер-ваальсовы связи (энергия - до 10 кДж/моль).

В реакто-пластах часть межмолекулярных связей заменена на прочные химические. Межмолекулярное взаимодействие фиксирует элементы полимерной структуры, подавляет гибкость цепных молекул и способствует повышению жесткости полимера, в итоге повышаются его плотность, температура плавления и уменьшается коэффициент линейного термического расширения.

Повысить энергию межмолекулярной связи можно разными способами.

Во-первых, этого добиваются путем увеличения полярности полимерных звеньев. Например, полярность винилхлорида больше, чем этилена, следовательно, энергия межмолекулярных связей в 
поливинилхлориде (ПВХ) больше, чем в полиэтилене (ПЭ), что и подтверждается большей прочностью ПВХ.

Второй путь заключается в создании трехмерной пространственной структурной сетки из ковалентных химических связей. На практике это может быть достигнуто введением в полимер химически активных компонентов (отвердителей) или радиационным облучением. Действительно, вулканизованный каучук прочнее исходного, а после облучения (в малых дозах) полиэтилен также прочнее исходного.

В-третьих, можно ввести в полимер высокодисперсный наполнитель, активно взаимодействующий с макромолекулами. Например, при введении сажи в резину прочность ее возрастает.

Другое направление изменения свойств полимеров заключается в ориентации макромолекул в направлении предполагаемого воздействия внешней силы. Она осуществляется вытягиванием полимерного материала в заданном направлении или другими способами. При этом увеличивается количество линейных молекул полимера, для разрыва которых необходимо преодолеть энергию межатомных связей.

Энергия активации вязкого течения полимера определяет ту энергию, которую сегмент должен получить в результате флуктуации тепловой энергии и которая необходима для отрыва сегмента от окружающих его соседей. Для примера запишем значения энергии активации для нескольких полимеров [4-5]

\begin{tabular}{|c|c|}
\hline Полимер & $U$, кДж/моль \\
\hline Полиэтилен & $46-53$ \\
\hline Полистирол & $92-96$ \\
\hline Поливинилхлорид & 146 \\
\hline Ацетат целлюлозы & 292 \\
\hline
\end{tabular}

Учитывая, что энергия химической связи С - С составляет 250 - 334 Дж/моль, можно гарантировать, что при переработке расплава полиэтилена не будет наблюдаться термодеструкции, а при переработке Ацетата целлюлозы - будет.

Энергия активации термодеструкции полимера на воздухе ниже, чем в вакууме, и составляет $92-96$ кДж/моль [6], а у полимера с концевыми триметилсилоксигруппами - 126 кДж/моль [7, С.488].

Изучим термодеструкцию образцов полиэтилена толщиной 0,1 мм на воздухе. Будем подвергать их воздействию естественной солнечной радиации, при перепадах температуры от 10 до $45{ }^{\circ} C$, в течение 150 дней (3600 часов). 
Как видим (рис.1) образцы сильно разрушены, деструкция краев образцов напоминает рваные края. Это связанно с тем, что края образцов были закреплены, и на них хоть и в незначительной степени но все же влияли дополнительно механические нагрузки.
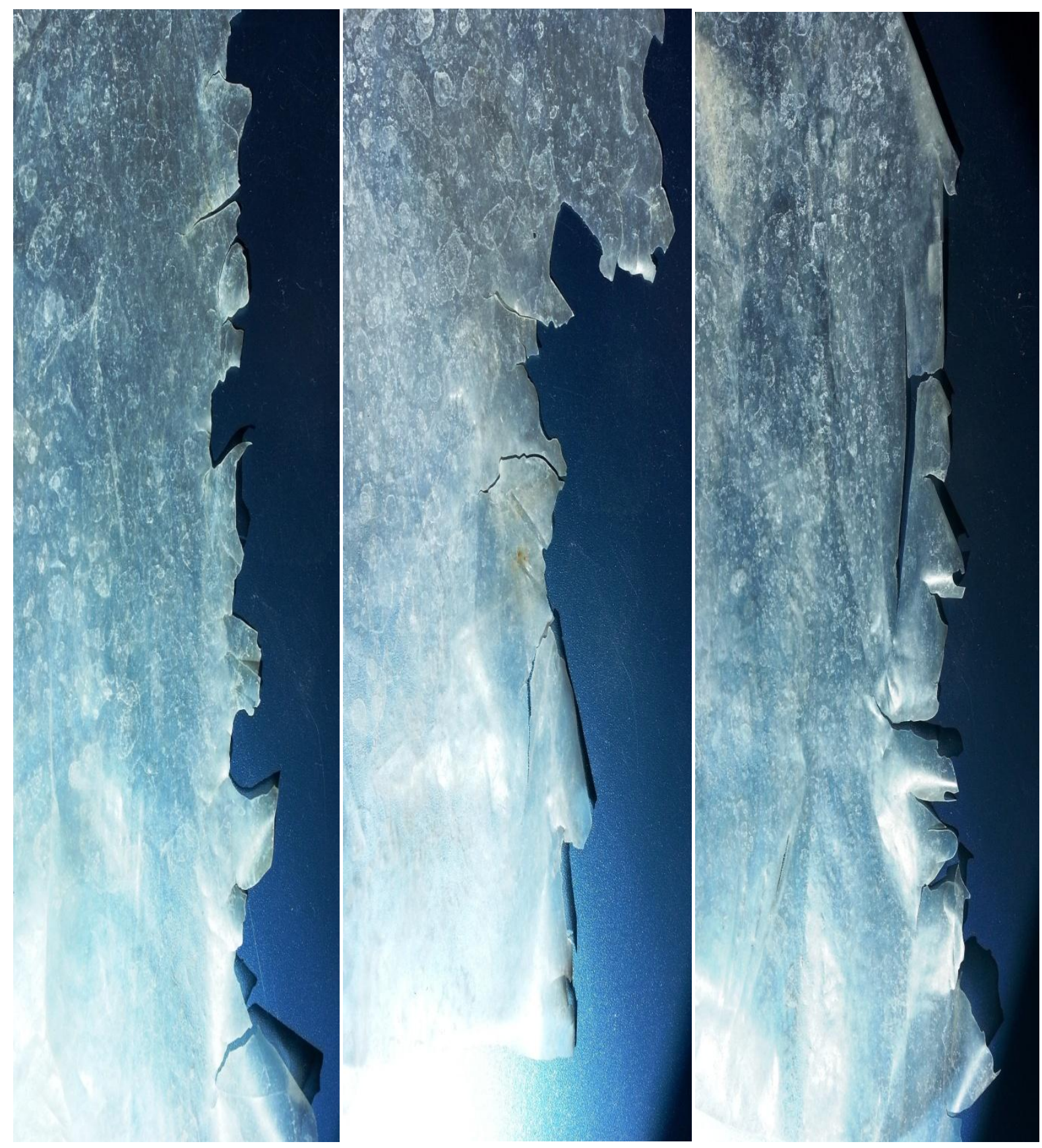

Рисунок 1 - Деструкция границы образцов.

Рассмотрим теперь образцы, в которых механические нагрузки отсутствовали вовсе (рис.2). Здесь наблюдаются своеобразные аттракторы, в которых разрушение происходило более активно, и это отчасти связано с ростом трещин в самом полимере. Согласно [1], скорость роста трещины и 
объединения плавающих дырок, может превышать скорость термодеструкции отдельных молекул, даже с учетом развития пористости материала. Именно этот процесс мы как раз и видим на наших образцах.
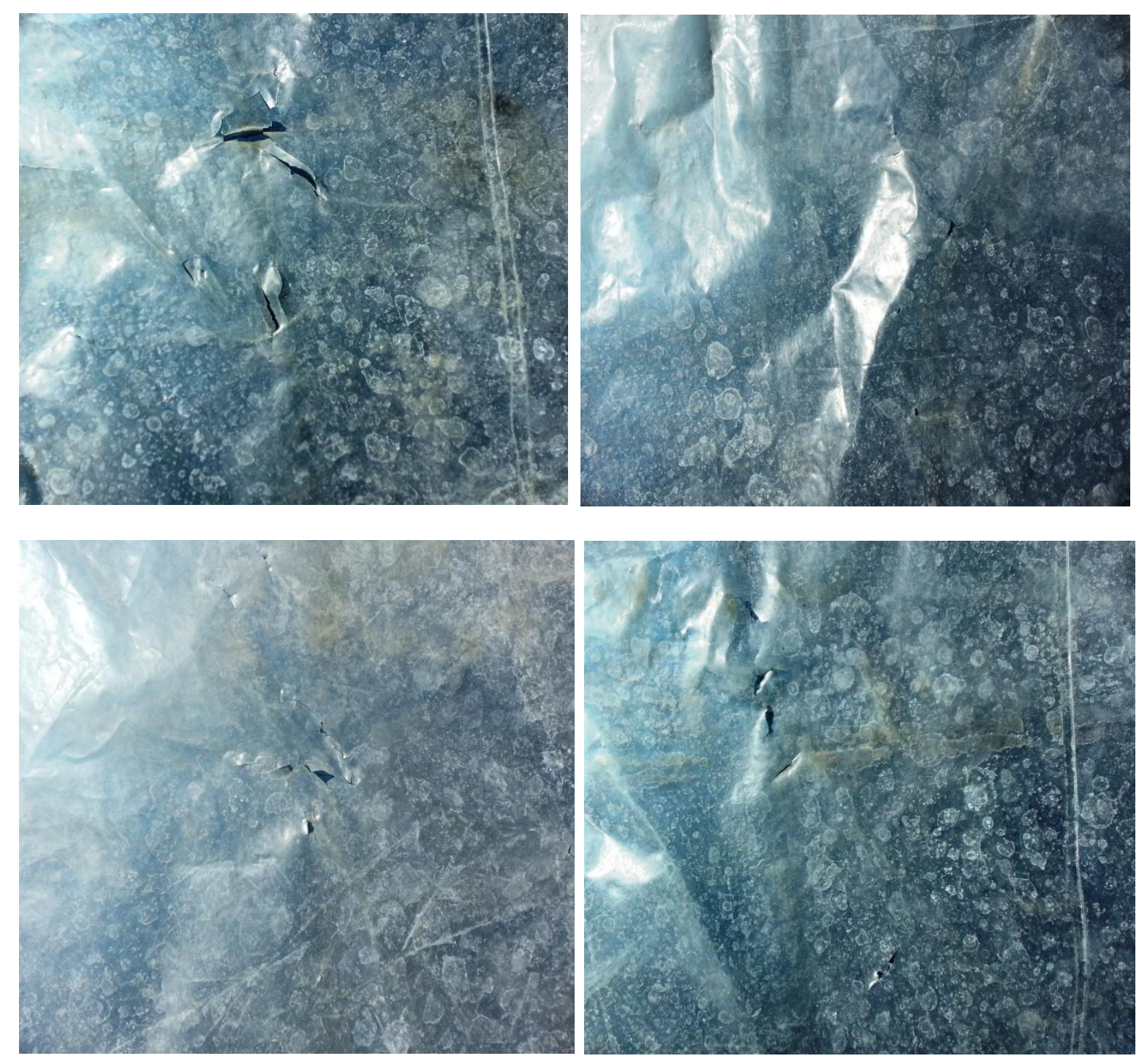

Рисунок 2 - Деструкция образцов без нагружения.

При увеличении (Рис.3), наблюдаются такие же неровные рваные края в местах начала термодеструкции. Это легко объясняется изменением свойств полимера в следствие термодеструкции и накопления положительных дилатаций в цепочках полимера.

Экспериментальные исследования показывают, что как при хрупком, так и при квазихрупком разрушении впереди трещины происходит разрыхление полимерного вещества [1]. Оно проявляется в образовании и накоплении перед фронтом трещины множества микрополостей и вторичных субмикротрещин. Трещина разрушения продвигается через заранее подготовленную среду, насыщенную микропорами. На первом 
этапе, пока скорость трещины не велика, движение трещины является изотермическим. По мере возрастания скорости, происходит переход ее к адиабатическому движению. Выделяющееся тепло в месте разрыва не успевает отводиться, происходит разогрев концевой области трещины, изза чего в конце флуктуационной стадиии, скорость трещины резко увеличивается, приближаясь к предельной скорости атермической стадии.
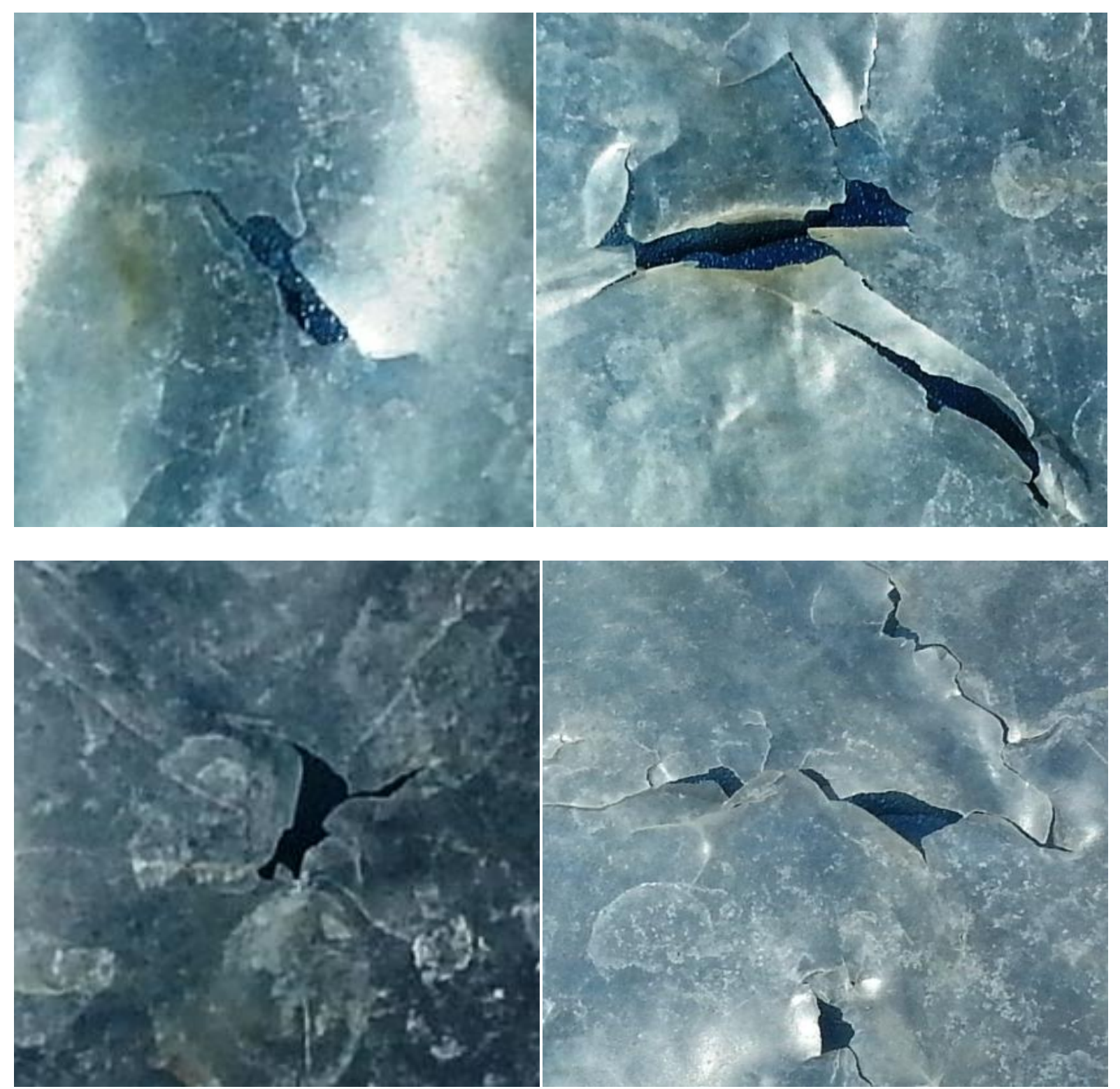

Рисунок 3 - Хрупкое разрушение образцов.

Вынужденная эластическая деформация, несмотря на уменьшение времени ее развития, «не успевает» за трещиной, размеры эластической зоны вначале «замораживаются», а с переходом к атермической стадии эластическая зона исчезает, и заключительный этап разрушения 
происходит по хрупкому механизму. Причем первоначальные разрывы мономеров чаще произсходят именно в местах сцепки на концах мономера Локальные микропоры - дырки, накапливаются в полимере, и возникают не повсеместно, а лишь в некоторых, как бы предрасположенных к этому местах[1]. Это явно показывает, что в микроструктуре материала есть некоторые «несущие» элементы, и пассивный наполнитель. «Несущие» элементы микроструктуры полимера - это химические связи главной валентности полимерных макромолекул и группы таких связей. Разрушение несущих элементов и составляет суть элементарных термофлуктуационных актов. Именно несущий каркас воспринимает и держит внешнее напряжение, находясь при этом, в постоянном тепловом движении. Образование дырок происходит в результате термофлуктуационного распада «слабых узлов» несущего каркаса.

Разработка математической модели процесса разрушения полимера, должна включать:

- определение несущего каркаса,

- нахождение слабых узлов,

- учет теплового движения,

- появление полостей и центров диллатации,

- нагрузки возникающие в клюве трещины.

\section{Литература}

1. Валишин А.А. Комплекс математических моделей механизма разрушения полимеров. -Диссертация ... доктора физико-математических наук : 05.13.18, Москва, 2007г., 421 с.

2. Природа науки. Постоянная Больцмана. [Электронный ресурс]. URL : http://elementy.ru/trefil/21104 (дата обращения: 20.07.2013).

3. Основные свойства полимеров и пластмасс. [Электронный ресурс]. URL : http://www.bibliotekar.ru/spravochnik-104-stroymaterialy/85.htm (дата обращения: 20.07.2013).

4. Бартенев Г.М., Зеленев Ю.В. Физика и механика полимеров. М.: Высш. школа, 1983. - 373 с.

5. Вязкое течение растворов и расплавов полимеров. -Теплофизика полимеров. [Электронный ресурс]. URL : http://softacademy.lnpu.edu.ua/Programs/fizika polimerov/Theme\%202/Secti on\%204.htm (дата обращения: 21.07.2013).

6. Активации термодеструкции. [Электронный ресурс]. URL : http://www.polymer-tech.ru/ref/aktivacii termodestrykcii.html (дата обращения: 21.07.2013).

7. Гармонов И.В. Синтетический каучук, 1976, 753 с. 